\title{
Study on higher vocational education talent cultivation measures under the background of new engineering
}

\author{
Fan Yiyu \\ Wenzhou Vocational \& Technical College, Wenzhou. 325035 \\ iuuiwe@qq.com
}

Keywords: new engineering. higher education. talent cultivation.

\begin{abstract}
Engineering education mixes various educational factors together creatively to make them match with and support each other, and this further prompts the function of the whole system from quantity superposition to quality leap and forms unique creativity and core competitiveness, which features in integration and innovation. Talents are primary resources for developing a new economy. And higher education is the primary productive force of technology, primary resource of talents and primary driving force of innovation, which should play an important and special role.
\end{abstract}

\section{Introduction}

Engineering education is closely connected with industrial development and support each other. The development of new industry depends on the engineering education to offer talents support in order to cope with the international competition and challenges of new technology and industry in the future and promote the economic restructuring and upgradation. In the perspective of new economy, this project studies the engineering talents training mode to develop new engineering, transform and innovate traditional engineering majors and meet the demands of talents support of new economy development. And it aims to further establish new engineering talent system in vocational education field and cultivate innovative professional engineering talents who have international perspective so as to achieve the goal—“Made in China 2025”.

\section{Analysis on core system of new industrial revolution}

In 2013, German government officially approved industry 4.0 project and put it into high-tech strategy 2020; Strategic Plan for Advanced Manufacturing Countries of America, Japanese Renaissance Strategy, French New Industry, Implementation Plan on Manufacturing Innovation 3.0 Strategy of Korea, Made in China 2025 and other plans aim to remodel industrial power, improve industrial competitiveness and keep ahead in the new round of industrial revolution by creativity. According to industry 4.0 project, the new enterprises will establish global network and combine machinery, storage system and production facilities into Control Program Support(CPS). In practical manufacture, these intelligent machines, storage system and production facilities can automatically exchange information, trigger operation and control each other separately, which promotes the whole industry process of manufacture, engineering, utilization of materials, supply chain and life cycle management to transform the manufacturing industry into an intelligent type, realize the change from central station control to distributed enhancement control and finally build highly flexible production mode of individuation and digital products and services. The definite core system are: (1) smart factory (2) autonomous robot (3) simulation (4) horizontal and vertical system integration (5) Industrial Internet of Things (6) network security (7) cloud computing (8) additive manufacturing (9) augmented reality (10) big data analysis.

New economy and new form of industryneeD NEW ENGINEERING TALENTS

Developing new economy needs distribute new engineering majors. New economy is short of talents because there are a lot of new industries and new formats rising in new economy such as Internet of Things, internet, big data, intelligent manufacturing, service manufacturing, cloud 
hospital, cloud medical service, internet security and intelligent security. And developing new economy needs innovation ability and integration ability of engineering talents. The essence of new economic development is the redistribution of elements and resources and reconstruction of reconfiguration of productive relations, and the key of it is innovation. New economy is a crossindustry and cross-discipline concept involving the first, second and third industries and appearing internet + and design + , where soft industry and hard industry mix together. And it extends to the high-end of industrial chain and value chain. From the aspects of the depending subjects, green and smart mass technology revolution has typical interdisciplinary fusion characteristics. Developing new economy needs individuation and diversification engineering personnel training mode. From the view of international experience, developing new engineering needs new engineering.

\section{Training objectives of core ability of vocational education new engineering students}

In 2005, Employment and Training Administration put forward a general capacity model as one part of "high growth industry employment training program" of President Bush. The general capacity framework is a nine-layer pyramid structure. According to the new trends of engineering development under the background of the fourth industrial revolution, by referring the Ernst and Lars ability requirement analysis method, this project group puts up the classification architecture of core capacity of new engineering students, that is, personal efficacy, knowledge ability, academic ability, technical ability and social skills.

\subsection{Core topic and new technology of industry 4.0 calls for new engineering talents}

Smart factory: It mainly studies the intelligent production system and process, the implement of networked distributed production facilities and comprehensive integration, automation and optimization production lines. It promotes the productivity and changes the traditional relationship between suppliers, producers and customers and the relationship between people and machine. Intelligent production: It mainly involves the production logistics management of whole enterprise, human-computer interaction and the application of 3D technology in industrial production process. Industry 4.0 strategy attracts small and medium-sized enterprises to join in, and make it become the user, the creator, provider and beneficiary of a new generation of intelligent manufacturing technology. Intelligent logistics: It integrates logistics resources mainly through the Internet, the Internet of things, the logistics network to make full use of the existing logistics resources providers and make demander gain service matching and logistics support fast.

\subsection{Study on interactive teaching strategy of vocational education new engineering}

Learning characteristics of digital natives: The contemporary university students are totally different from previous learners, and they are called "digital natives" or "net generation". With reform pace of science and technology accelerating, the new generation of college students come to the campus, having resources, skills, and expectations totally different from those of past students, and pursuing knowledge and experience by an unprecedented method. Digital natives college students increasingly show some unique features: In terms of study, they like game-based learning and direct feedback; As for social contact, they tend to network interaction based on community; On work, they are good at multitask and nonlinear methods and are proficient in technology; As for thinking, they are good at scanning, information visualization and critical thinking.

Teaching strategy of new engineering: New engineering construction promotes "One Belt and One Road” strategy implement. Using new engineering education system stores innovative talents, helps to connect through the Asia-Europe economic artery and reshape the surrounding economic geography; Services begin the inter-regional cooperation, the industry transforms orderly and the structure transforms and upgrades to establish mutually beneficial and win-win development new pattern. And the safety strategy also promotes to reduce the influence of Cold War mentality on world pattern. Combining cluster development and innovation achievements transformation active characteristics of high and new technology industry, it establishes the majors of the modern engineering construction. And it helps to establish the relative industries of biological medicine of 
Big health system, aerospace, intelligent manufacturing, the talents cultivation of technology innovation platform and state think-tank which have important international influence.

\subsection{Study on talents training mode of vocational education new engineering}

(1) Optimize and improve the training standard of new engineering talents. Combining intellectual and non-intellectual factors, the talents training mode sets up specification requirements covering knowledge, ability and quality these three dimensions. It focuses on the storage of interdisciplinary domain knowledge, multidisciplinary research ability and cultivation of interdisciplinary cooperation spirit, making the training talents acquire multidisciplinary thinking, compound knowledge, and ability and quality.

(2) Explore crossed and compound talents training mode. The talents training mode establishes the building mechanism of featured course. Based on classical textbook, it embraces the multidisciplinary new knowledge and new technology and optimizes curriculum content from the perspective of "knowledge map"; It develops and implements the opening mechanism of general core curriculum and interdisciplinary courses to break through simple subject barriers and constructs professional course group mode of inter-disciplines along the question cues to expand read coverage of interdisciplinary professional courses. It aims to realize the integration education between different subjects and guide students to build broad and deep knowledge basis; It expands "overpass" type composite and professional training mechanism and selects the great students under the relevant professional knowledge background to study a new engineering specialty.

(3) Establish innovation and entrepreneurship education system. It integrates innovation and entrepreneurship education elements organically in engineering education training program, combining innovation and entrepreneurship general course group with a professional curriculum system and combining innovative thinking training with innovation and entrepreneurship practice ability training; In terms of teaching mode, it extends the space for innovation and entrepreneurship training with the help of college student pioneer park and local research institutes.

(4) Use deep learning mode to train talents. Deep learning refers to a kind of learning method in which learners use the advanced cognitive skills(such as analysis, synthesis, problem solving and metacognitive ability) to deal with information and build a long-term and profound understanding. It involves the critical analysis of the new ideas, combines new ideas and known concepts and principles, which can be applied to solve the problems in the new situation. Deep learning is the key to develop core talents and study results.

(5) Use blending learning mode to train talents. Blending learning brings the shift in perspective to higher education and remodel the learning process pf students continuously.

\section{Conclusion}

According to the new trend of project development under the background of the fourth industrial revolution and referring Ernst and Lars capacity demand analysis method, the classification architecture of core ability of new engineering students is put forward.

Education and teaching mode reform in new engineering. Learning is the basic mode of human existence and it depends on the social interaction and meaning creation. Only by participation, communication and experience, can students require ability to cope with the complicated and rapidly changeable world challenge. Teaching model should transform to student-centered comprehensive and applied learning from teacher-centered classroom teaching; Learning mode should transform to the customizing deep learning; Teaching environment should change to become blending and visual teaching; And teaching management system should transform to credit mutual recognition policy which adapts the remote learning and cross-school learning.

\section{Acknowledgements}

The project of Wenzhou philosophy and Social Science (17wsk161) 


\section{References}

[1] Wang hua, Design of the BD2 / GPS dual-mode vehicle navigation terminal system, Digital technology application, 2013(3).

[2] Xia feng, Hu da, The design of the urban car GPS navigation system, computer and modernization,2004(3).

[3] Zhao jun, the design of the vehicle intelligent terminal of the Open-pit coal mine harvester, Electronics world, 2017.1.

[4] Teng wen, The optimal path search algorithm research of the vehicle navigation system. Automation and instrumentation, 2016.12.

[5] Yang lin guo, Design of a new type of car terminal positioning navigation system Based on GPS, BlueTooth, GPRS, Journal of anhui vocational \& technical college,2011.2.

[6] Zhou xin,Zhu lan,Wu jiang etc. EPON network research in intelligent electric communication network with si chuan. Post and telecommunications design technology , 2011,(1):5357.DOI:10.3969/j.issn.l 007-3043.2011.01.013.

[7] Lin mingyu, Xiang wanqin. With the electric communication network technology application research [L]. Journal of chong qing electric power college 2012,17(5):70-73 